\title{
How not to get lost in the literature woods?
}

Recent decades have seen a dramatic increase in scientific publications and journals (Laakso et al., 2011; Ware and Mabe, 2015) and, consequentially, the editorial community (Espin et al., 2017). The latter appears to be a crucial guide in the literature, as scientific editors not only organize manuscript evaluation processes, but also invite experts for peer review and help choose new editors (Espin et al., 2017). Editors sometimes even create the must-read lists of published research (Courchamp and Bradshaw, 2018), thus shaping both the readership and the authorship of published papers. This selection may thus form the direction of development in the whole discipline. However, the demographic and geographic representation of scientists in editorial boards of international journals is highly biased towards men and a few developed countries, with an overwhelming contribution from USA and UK representatives (Mazov and Gureev, 2016; Espin et al., 2017). Hence, the directionality in publications and literature recommendations might be severely biased (Bruna, 2018). A similar situation might be observed in national-level journals with overrepresentation of editorial board members from the home country. Therefore, in order to increase diversity within its editorial board and avoid biases, Biological Communications has already started board member rotation and invites readers to nominate themselves, especially if the nominee can significantly broaden the scope of the journal in a field not adequately covered by the existing editorial board members.

Another way of focusing the attention of the readership on certain publications and extending the capability of the editorial board is to organize themed special issues for publication of sets of review and original papers on the same topic, written by experts in that field. This is a further step towards better orientation in the literature and broader readership (Foxe and Bolam, 2017). In this issue, therefore, we present three mini-reviews in the field of neuroscience, with a particular emphasis on neurodegenerative and neurodevelopmental diseases. The next issue will be entirely devoted to plant science, and we will continue to organize special issues in the future. This is a particularly promising approach, since it allows us to invite guest editors with additional topical expertise, which extends the expertise of the regular board members. From now on, suggestions of topics for future special issues of Biological Communications are being accepted.

The increasing number of publications globally also has some side effects. The emphasis in leading journals on novelty in publications and high competition for space neglect the necessity of replication and complementary studies in modern science to avoid retractions due to found mistakes or falsifications and, even worse, long-lasting citation of wrong conclusions. Indeed, sometimes many papers cite a fact only shown in a single paper and not independently verified. On the other hand, there are often situations in science when two research groups independently present the same or similar results, but only the first succeeds in publication, while the second paper is usually rejected due to lack of novelty. I myself, with co-authors, have fallen into this trap by submitting a manuscript to PLOS Biology replicating, complementing, and actually extending a study which was published in another journal just a week before our submission. Half of our work was later published, while the other half is still unpublished. To my surprise, I read recently in PLOS Biology an editorial claiming new policy regarding complementary studies (Alvarez-Garcia et al., 2018). The editors of PLOS Biology underline the importance of recognizing and validating well-supported, significant research findings as well as the researchers who did not cross the finish line first, but undertook the same effort and maybe even achieved greater progress in their work. To support this valuable and important tendency, Biological Communica- 
tions from now on considers timely made additions and extensions of earlier published work as a part of our general policy aimed at visibility of research. We also introduce a new journal section, "Communica- tions Arising," for discussion of important findings published in our and other journals, placing them in broader content, adding important arguments pro and contra. We believe all these innovations will help readers to navigate the literature, and authors to make their research visible and read. This is now very important, because "research that is not read does not exist" (Donovan 2017).

Yegor Malashichev, Editor-in-Chief of "Biological Communications"

\section{References}

Alvarez-Garcia, I., Ganley, E., Gasque, G., Gross, L., Jiang, D., Grone, B., Whiteman, L., Richardson, L., Roberts, R. and Wijayatilake, H. 2018. The importance of being second. PLoS Biology 16(1):e2005203. https://doi.org/10.1371/journal.pbio.2005203

Bruna, E. M. 2018. Editorial board members are a non-random sample of ecological experts. Nature Ecology and Evolution (2):202. https://doi.org/10.1038/s41559-017-0443-9

Courchamp, F. and Bradshaw, C. J. A. 2018. 100 articles every ecologist should read. Nature Ecology and Evolution 2:395-401. https://doi.org/10.1038/s41559-017-0370-9

Donovan, S. K. 2017. Predatory journals: Research that isn't read doesn't exist. Nature 550(7675):188. https://doi.org/10.1038 $1550188 \mathrm{e}$

Espin, J., Palmas, S., Carrasco-Rueda, F., Riemer, K., Allen, P. E., Berkebile, N., Hecht, K. A., Kastner-Wilcox, K., Nunez-Rugueiro, M. M., Prince, C., Rios, C., Ross, E., Sangha, B., Tyler, T., Ungvari-Martin, J., Villegas, M., Cataldo, T.T. and Bruna, E. M. 2017. A persistent lack of international representation on editorial boards in environmental biology. PLoS Biology 15(12):e2002760. https://doi.org/10.1371/journal.pbio.2002760

Foxe, J. J. and Bolam, J. P. 2017. On open access, special issues and strategies for increasing the readership of your neuroscience research. European Journal of Neuroscience 46:2791-2792. https://doi.org/10.1111/ejn.13774

Laakso, M., Welling, P., Bukvova, H., Nyman, L., Bjork, B.-C. and Hedlund, T. 2011. The development of Open Access journal publishing from 1993 to 2009. PLOS ONE 6(6):e20961. https://doi.org/10.1371/journal.pone.0020961

Mazov, N. A. and Gureev, V. N. 2016. The editorial board of scientific journals as a subject of scientometric research: a literature review. Scientific and Technical Information Processing 43(3):144-153. https://doi.org/10.3103/s0147688216030035

Ware, M. and Mabe, M. 2015. The STM report: An overview of scientific and scholarly journal publishing. The Hague, The Netherlands: International Association of Scientific Technical and Medical Publishers. http://www.stm-assoc.org/2015_02_20_ STM_Report_2015.pdf (accessed 28/04/2018) 